\title{
Topobathymetric Data for Tampa Bay, Florida
}

\author{
By D. Tyler ${ }^{2}$, D.G. Zawada', A. Nayegandhi', J.C. Brock', M.P. Crane', K.K. Yates', and K.E.L. Smith'
}

$82^{\circ} 35^{\prime} 0^{\prime \prime} \mathrm{W}$

$82^{\circ} 30^{\prime} 0^{\prime \prime} \mathrm{W}$

(meters)

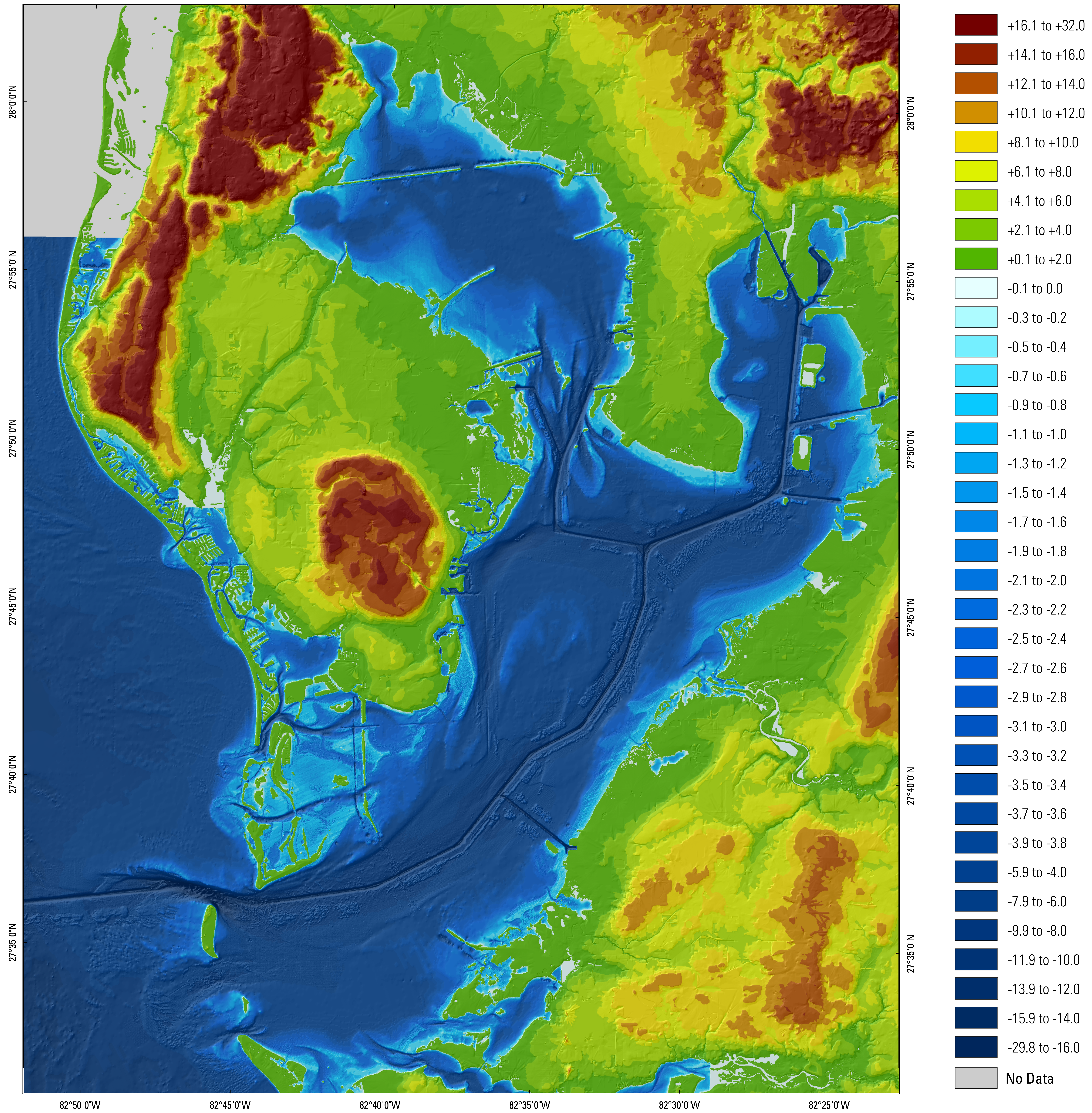

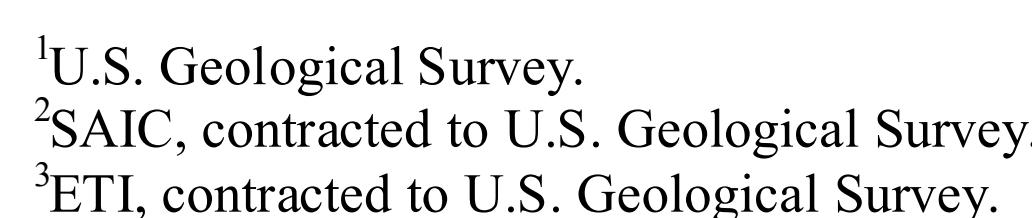

Open-File Report 2007-1051 (revised)

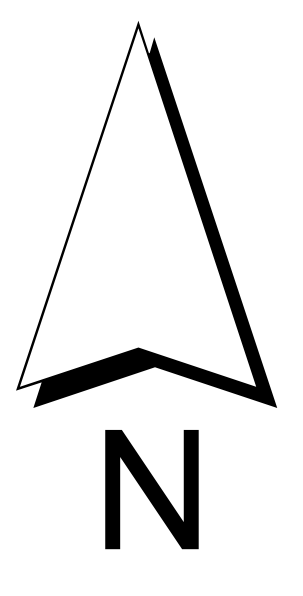

Suggested citation:

Tyler, D., Zawada, D.G., Nayegandhi, A., Brock, J.C., Crane, M.P., Yates, K.K and Smith, K.E.L., 2007, Topobathymetric data for Tampa Bay, Florida: U.S. Geological Survey Open-File Report 2007-1051 (revised)

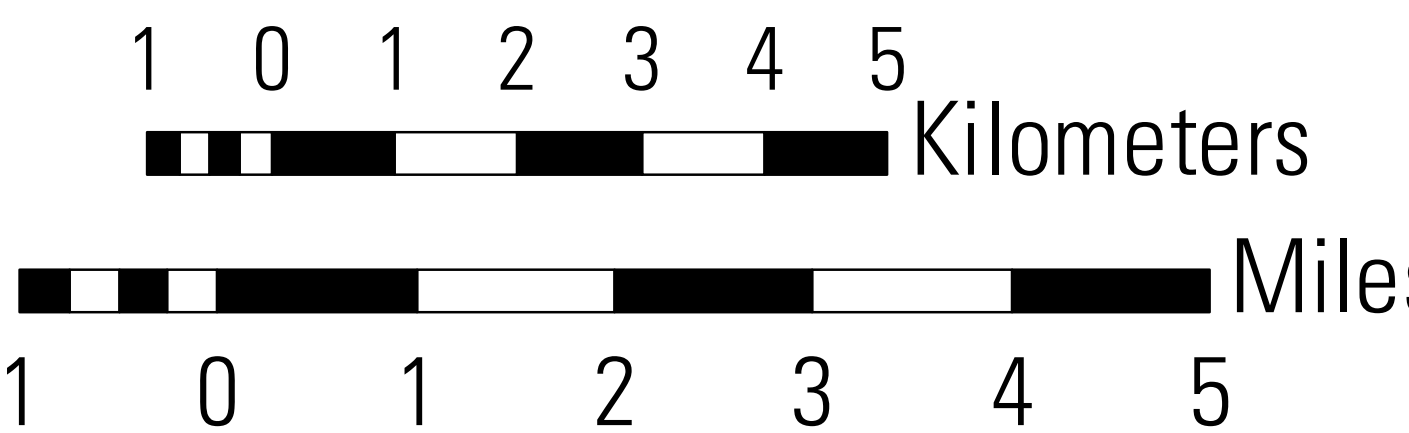

Topobathymetric data (a "topobathy") are a merged rendering of both topography (land elevation) and bathymetry (water depth) to provide a single product useful for inundation mapping and a variety of other applications. These data were developed using one topographic and two bathymetric datasets collected at different dates. Topography was obtained from the U.S. Geological Survey's (USGS) National Elevation Dataset (NED) Bathymetry was provided by NOAA's GEOphysical DAta System (GEODAS). For several nearshore areas within the bay GEODAS data were replaced with high resolution bathymetry acquired by NASA's Experimental Advanced Airborne Research Lidar (EAARL). These data and detailed metadata can be obtained from the USGS Web site: http://gisdata.usgs.gov/website/topobathy/. Data from EAARL and NED were collected under the auspices of the USGS Gulf of Mexico Integrated Science Tampa Bay Study http://gulfsci.usgs.gov/.

Internal Map IO Us 